\title{
Foreword
}

\section{Perioperative Care of the Trauma Patient: New Concepts Since Wartime Learning}

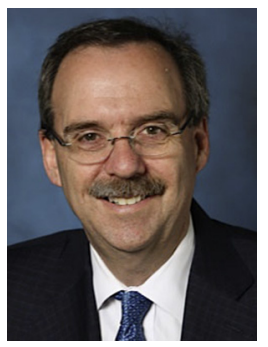

Lee A. Fleisher, MD, FACC, FAHA Consulting Editor

Trauma care has evolved significantly since its development during wartime, and that includes the role of the anesthesiologist and the influence beyond simple intraoperative resuscitation. In this issue of Anesthesiology Clinics, a series of articles has been commissioned that address the acute care, intraoperative management, and longterm implications. As enhanced recovery after surgery has become commonplace for elective surgery, an article on the implications to trauma care has been included. There are also very timely articles on issues of care in the era of the opioid epidemic, long-term implications of care, and hospital planning for an active shooter incident. Finally, the implications of trauma care to home are discussed.

In order to commission an issue on trauma care, I have turned to a former faculty colleague and national expert, Maureen McCunn, MD, MIPP. Maureen is currently Professor of Anesthesiology at the University of Maryland and a member of the Division of Trauma Anesthesiology at the R Adams Cowley Shock Trauma Center. She has leadership roles as a member of the Board of Directors of the Trauma Anesthesiology Society, Chair of the American Society of Anesthesiologists (ASA) Committee on Trauma, and a member of the Eastern Association for the Surgery of Trauma Seniors Committee. She has solicited two outstanding colleagues to assist in editing this issue. Mohammed lqbal Ahmed, MBBS is Associate Professor of Anesthesiology at the University of Texas Southwestern Medical Center and a Staff Cardiac Anesthesiologist at Children's Medical Center and Children's Health System of Texas. He serves on the ASA Committee on Trauma and Emergency Preparedness and the Society for Pediatric Anesthesia Committee on International Education and Service. Catherine M. Kuza, MD is an Assistant Professor in the Department of Anesthesiology at Keck School of 
Medicine of the University of Southern California. She is a member of the Trauma Anesthesiology Society and has served on the ASA Committee on Trauma and Emergency Preparedness.

Lee A. Fleisher, MD, FACC, FAHA Perelman School of Medicine University of Pennsylvania 3400 Spruce Street, Dulles 680

Philadelphia, PA 19104, USA

E-mail address: Lee.Fleisher@uphs.upenn.edu 